\title{
Realization of the Right to Employment to the Citizens with Special Needs in the Russian Federation
}

\author{
Elena Blagireva \\ Russian State Specialized Academy of Arts \\ Moscow, Russia \\ rgsai@mail.ru
}

\begin{abstract}
The paper analyzes social relations associated with the implementation of the right to employment to the citizens with disabilities in the Russian Federation and identifies the main mechanisms of the Russian Federation legislation improvement in this field.
\end{abstract}

Keywords-quality of life; education; items of cultural value and cultural benefits; accessibility; providing special conditions; competitiveness; efficiency

\section{INTRODUCTION}

Nowadays, there are about 12 million people with disabilities living in the Russian Federation and the majority of them are of retirement age.

The labor potential of the citizens with special needs is currently less than one million of working age, which makes $25 \%$ of their total number. In general, there are 33,000 quotas to employ the people with disabilities. However, disabled people fill only 11,000 of jobs, while about 22,000 jobs are not in demand by the disabled [1]

The major problem is that the economy provides jobs for the people with disabilities as a residual and frequently these are low-skilled and underpaid jobs.

Moreover, there should be close interrelation between vocational training for the people with disabilities and their employment. Thus, the priority areas of training should include those in demand in the labor market and well-paid, accordingly.

The problem of employment of the people with disabilities in the Russian Federation is given special attention at the state level. In particular, the problems of disabled people employment were in the spotlight at the meeting of the Russian Federation President with the representatives of public organizations for the people with disabilities and professional communities held on December 5, 2017 at the Russian State Specialized Academy of Arts.

As a result of the meeting, the Russian Federation Government was entrusted to adjust training programs for the people with disabilities and to improve the employment mechanisms in business and production, so that the jobs are provided for the disabled people according to their qualification rather than as a residual [1].
When dealing with the issues of increasing the employment level of the people with disabilities, particular emphasis should be placed on improving the interaction between educational organizations and employers.

Ensuring the constitutional right to employment to the citizens with special needs is a national task and a top priority in Russia.

The problem of employment is a major one in the integrated process of rehabilitation of people with disabilities.

\section{MEASURES TO IMPROVE THE EMPLOYMENT MECHANISM}

The Russian Federation legislation establishes the required level of legal guarantees to the employment of the disabled people.

For instance, Article 21 of Federal Law No. 181-FZ "On Social Protection of Disabled People in the Russian Federation" of November 24, 1995envisages that for the organizations employing more than 100 people, the legislation of the constituent entity of the Russian Federation establishes a quota for disabled people employment of 2-4\% of the average number of employees. For the organizations employing 35 to 100 people, a quota up to $3 \%$ for disabled people employment can be established by the constituent entity [2].

According to the Law of Moscow of December 22, 2004 No. 90 "On workplace quotas" for the organizations whose average number of employees exceeds 100 people, a quota to employ people with disabilities is set at the $2 \%$ level of the average number of employees [3]. Meanwhile, in the Yaroslavl region, for the employers with more than 100 workers, the quota to employ disabled people is $4 \%$ of the average number of employees [4].

Nevertheless, even in case of available vacancies in the labor market and job quotas, in fact, the employment of the people with disabilities is difficult, as the jobs provided do not account for such people's peculiarities of life activity restrictions.

The government is taking certain measures aimed at increasing the level of disabled people employment up to the average for all the categories of unemployed. 
Thus, by 2020, the Ministry of Labor of Russia sets the goal of doubling the people with disabilities employment rate [5].

The above-mentioned ambitious task will be solved only in case of government structures and employers coordinated work and applied integrated approach to solving this complex problem.

Firstly, the Ministry of Labour of the Russian Federation has created a draft law to provide necessary support to the citizens with special needs when dealing with employment issues. It presupposes the establishment of a mechanism to implement regional programs for assisting the citizens who experience difficulties in finding job, including the people with disabilities by the state employment services authorities [6].

Secondly, the fundamental change in the mechanism of quoting jobs for the people with special needs is being worked out. It implies encouraging the employers to create new work places and preserve the existing ones for this category of population.

Thirdly, the incentives for the employers who take the people with special needs beyond the existing quotas are currently being developed.

What is more, in order to provide methodological assistance to public institutions of the employment service, employers, professional communities, educational and other organizations on how to prevent the cases of discrimination against people with disabilities in employment issues, the Order by the Ministry of Labour of the Russian Federation No. 777 of November 9, 2017 approved recommendations for identifying signs of discrimination in employment [7].

The Ministry of Education and Science of the Russian Federation is working actively to provide vocational guidance and professional training, in particular, through Abilympics National Championship of Professional Skills Competition for people with disabilities.

The Ministry of Culture of the Russian Federation, in its turn, coordinates the activities of the cultural-sector organizations aimed at maximizing the employment rate for the persons with disabilities.

The problems of safeguarding the rights of people with disabilities, including the right to work, are constantly being monitored by the Ministry of Culture of the Russian Federation.

To ensure the rigorous implementation of the legislative provisions of the Russian Federation and the regulatory legal acts concerning the employment of the persons with disabilities and provision of accessible environment for these people, the Ministry of Culture of the Russian Federation assigns the personal responsibility to the managers of the cultural-sector organizations.

The employment rate for persons with disabilities is included in the plans of measures ("the road maps") for improving the accessibility of facilities and services of the cultural-sector organizations by the persons with disabilities.
In the area of culture and the arts, a unique staff training system has been developed, within the framework of which the trainees participate in the activities of the creative groups even in the course of studying the educational program and doing the internship, which in most cases guarantees their job placement after graduating from the university.

At the same time a significant number of the academic teaching staff in the cultural-sector higher educational establishments works simultaneously at the cultural institutions (theaters, concert organizations, etc.), which also contributes to the further job placement of the graduates at these cultural institutions.

In dealing with the topic of providing employment in the cultural-sector organizations to the persons with disabilities, it is necessary to take into account the specifics of activities performed at these organizations, which are characterized by imposing special requirements on the employees in relation to health conditions and physical parameters, for which cause, the persons with disabilities are not eligible for work in a number of job positions.

According to the data obtained by the Ministry of Culture of the Russian Federation following the results of monitoring the accessibility of the cultural goods for people with disabilities in 2017, the hiring quotas for the persons with disabilities were allocated by more than $50 \%$ of the culturalsector organizations. The number of the employed people with disabilities amounts to 14,808 persons.

While implementing the measures aimed at solving the problems of access to employment by disabled persons, adaptation and job placement, the support of the disabled peopled is provided for and is being organized.

For development of inclusivity in terms of provision of employment to the disabled persons, the activities conducted by the socially-oriented non-profit organizations are very important, especially when it comes to support in finding employment, facilitating adaptation and job placement involving personal couches and technical assistants.

The efficiency of the supporting measures taken by the social organizations can be improved by means of providing the targeted aid in facilitating the employment involving personal assistants attending the disabled person in the process of searching for a job, finding employment and accommodating to a workplace.

Currently, the socially-oriented non-profit organizations providing the additional targeted services in the area of assistance in employment of the disabled persons, in particular, through the disabled people support service with the purpose of finding employment for them, perform their activities in the city of Moscow, Bryansk, Tambov, Nizhny Novgorod, Sverdlovsk, Stavropol and Krasnoyarsk regions, as well as in the number of other constituent entities of the Russian Federation.

To improve the efficiency of cooperation between the non-profit organizations and the state authorities, the disabled people support services have been established in the number of constituent entities of the Russian Federation with 
the purpose of providing assistance in finding employment, ensuring the right of the persons with special needs to professional rehabilitation, integration in the society, in particular to the career guidance, professional training and employment.

\section{CONCLUSION}

In order to carry out the systematic work on increasing the employment of the people with disabilities in the area of culture and the arts, the Ministry of Culture of the Russian Federation has taken the following measures:

1. A database is produced containing the job vacancies at the cultural-sector organizations of all organizational and legal forms, including the job vacancies for the persons with disabilities [8]. This database of job vacancies is actively used both by the citizens seeking employment, and by the employers.

At present, the work on creating regional databases of job vacancies offered by the cultural-sector organizations is being conducted at the level of cultural authorities of the constituent entities of the Russian Federation;

2. The additional conditions are being created for motivating people with disabilities to engage in creative activities, and also a system is being refined for finding and supporting of young talents with the purpose of their professional becoming and development, in particular through creating the all-Russian database of the winners of the art competitions with inclusion of persons with disabilities;

3. Under consideration is the issue of creating an Inclusive Art Centre as an experimental platform for spreading the innovative inclusivity methods and practices of following the art-related educational programs, sharing professional experience, creative achievements, as well as job placement of the creatively gifted persons with disabilities.

\section{REFERENCES}

[1] Transcript of the meeting of the Russian Federation President, V.V. Putin, with the representatives of the community of persons with disabilities at the Russian State Specialized Academy of Arts on December 5, 2017 // Official website of the President of the Russian Federation [Electronic resource]. Access mode: $<$ http://www.kremlin.ru/> (access date: 6/12/2017).

[2] On Social Protection of Persons with Disabilities in the Russian Federation: Federal Law No. 181-FZ dated November 24, 1995 // Collected legislation of the Russian Federation. - 1995. - No. 48. - p. 4563.

[3] Onjob quotas: Law of the city of Moscow No. 90 dated December 22, 2004// Vestnik Mera I Pravitelstva Moskvy ("Bulletin of the Mayor and the Government of Moscow"). - 2005. - No. 3.

[4] Onjobquotas: Resolution of the Governor of Yaroslavl region No. 859 dated December 21, 2004// Gubernskie Vesti (“Gubernial News") 2004. - No. 71

[5] Transcript of the speech of the Minister of Labourand Social Protection of the Russian Federation, Maksim Topilin, at the Russian Federation Government session // Official website of the Ministry of Labour and Social Protection of the Russian Federation [Electronic resource].
Access
$<$ https://rosmintrud.ru/employment/resettlement/2>(access 6/12/2017).

[6] Draft Federal Law "On Amendments to Law No. 1032-1 of the Russian Federation "On Employment in the Russian Federation" dated April 19, 1991// Unified Portal for Publishing Information about Preparation of Draft Regulatory Legal Acts by the Federal Executive Authorities and the Results of their Public Discussion [Electronic resource]. Access mode: $<$ http:www.regulation.gov.ru>(access date: 6/12/2017).

[7] On the approval of methodological recommendations for identification of signs of discrimination of people with disabilities when dealing with the issues of employment: Order of the Ministry of Labour of the Russian Federation No. 777 dated November 9, 2017 // Official Documents in Education, 2017, No. 33.

[8] Database of job vacancies at the organizations in the area of culture and the arts of the Russian Federation // Official website of the Ministry of Culture of the Russian Federation: The Department of Science and Education section. [Electronic resource]. Access mode: $<$ http://mkrf.ru/aktual/vacancies> (access date: 17/11/2017).

[9] Yakupov A.N., Blagireva E.N. Accessibility of Cultural Goods for the Persons with Disabilities in the Russian Federation in 2016: scientific research// A.N. Yakupov, E.N. Blagireva. - M.: Nauchnaya Biblioteka ("Scientific Library") Publishing House. 2017 - 774 pages 